\title{
0 aspecto social das ciências e a defesa da educação: Uma leitura contemporânea da epistemologia histórica de Gaston Bachelard ${ }^{1}$
}

\author{
The social aspect of sciences and the defense of \\ education: A contemporary reading of the historical \\ epistemology in Bachelard's work
}

\author{
Maria Helena Silva Soares \\ Doutoranda em Filosofia \\ PPGFIL UERJ \\ helenastraub@gmail.com
}

Recebido em 23/08/16

Aceito em 17/10/16

Para citar este artigo: SOARES, Maria Helena Silva. O aspecto social das ciências e a defesa da educação: Uma leitura contemporânea da epistemologia histórica de Gaston Bachelard. Em Construção. vol. 1, No. 1, 2017, pp. 51-68. DOI:10.12957/ emconstrucao.2017.28124

1 Este artigo tem sua origem em minha dissertação de mestrado, intitulada "O problema da objetividade em Gaston Bachelard: um estudo acerca da fenomenotécnica e do realismo científico", defendida em 2015 no Programa de Pós-Graduação em Filosofia da UERJ - PPGFIL/UERJ.

\section{Resumo}

O presente artigo pretende abordar o aspecto social das ciências na epistemologia histórica de Bachelard por meio de sua defesa e valorização da educação. Esperamos responder por meio da defesa bachelardiana dos valores e da vocação científica às críticas que afirmam não ver em sua filosofia questões que ultrapassam o âmbito cognitivo da produção nas ciências. Para isso, realizamos uma análise comparada das contribuições filosóficas de Gaston Bachelard e da perspectiva dos Science Studies, a fim de apresentarmos os pontos de encontro e afastamento entre as duas abordagens. Ensaiamos, neste trabalho, provar que há uma proposta ético-política na epistemologia bachelardiana, qual seja a sua defesa da educação científica. Deste modo, buscamos não apenas corroborar nossa tese de que é possível, a partir de Bachelard, fazer uma leitura social da epistemologia histórica, como também defender a atualidade de seu pensamento.

Palavras-chave: Bachelard - Science Studies - epistemologia histórica - educação

\section{Abstract}

This article aims to address the social aspect of science in the historical epistemology of Bachelard through a comparative reading alongside contemporary science studies. Therefore, we conducted a comparative analysis of the philosophical contributions of Gaston Bachelard and the perspective of Science Studies in order to introduce the points of agreement and disagreement between the two approaches. We hope to answer Bachelard's defense of the scientific values and vocation to the criticism that his philosophy does not discuss issues beyond those pertaining to the cognitive scope of science production. We attempt, in this work, to show that there is an ethical and political proposition in Bachelard's epistemology, which is his defense of science education. Thus, we seek not only to confirm our thesis that it is possible, through Bachelard, to make a social reading of historical epistemology, but also to defend the relevance of his thought.

Keywords: Bachelard - Science Studies - historical epistemology - education 


\section{Introdução}

A filosofia de Gaston Bachelard (1884-1962) é conhecida por suas duas abordagens: a epistemológica e a poética, ou, como sugerem seus escritos, a sua obra diurna e a noturna. A primeira reflete sobre as produções científicas dos séculos XIX e XX, já a segunda sugere um retorno à literatura para produzir um estudo sobre a imagem. Este dualismo fez com que durante muito tempo sua epistemologia fosse considerada ingênua em relação aos aspectos sociais e políticos que subjazem nas práticas científicas. Estas críticas mostram um certo desconhecimento da totalidade da obra bachelardiana, que promoveu uma ressignificação de conceitos fundamentais para a teoria do conhecimento, como no uso da noção de progresso como processo, da objetividade como fim e não como pressuposto e da fenomenotécnica como construção técnica de objetos científicos. Além disso, Bachelard também defendeu o erro, a especialização, a cidade científica e a descontinuidade histórica (a ruptura) como os verdadeiros motores do que ele entende por progresso científico.

Partir da análise do erro como o motor da história do conhecimento, ou seja, afirmar uma epistemologia histórica, não diferenciaria por si só a filosofia de Bachelard do pensamento que acompanhava a época. Mais do que pressupor um novo método historiográfico para a epistemologia, Bachelard afirmou uma ruptura no próprio conceito de história das ciências ao relacioná-la com a noção de progresso descontínuo. A descontinuidade se torna uma característica da história da razão. "A razão, felizmente incompleta, já não pode dormir na tradição, já não pode contar com a memória para recitar suas tautologias" (BACHELARD, 1972a, p.14). O espírito, ou a razão, científico trabalha em uma eterna luta com os outros e consigo mesmo, uma vez que precisa provar e colocar-se à prova sem cessar. Assim, a batalha da razão não se dá apenas contra a religião ou a ordem estabelecida por um poder, mas também contra sua própria tradição, contra sua história.

O novo espírito científico (1934), uma de suas obras mais citadas, faz uma breve exposição do processo histórico das ciências ser marcado por retificações, ou seja, uma constante correção dos erros passados. Nesta obra, Bachelard também apresenta sua concepção de progresso, que se destaca das teorias do conhecimento em voga na época por seu caráter descontínuo. Além disso, ele participa, no mesmo ano, 1934, do VIII Congresso Internacional de Filosofia, em Praga, do qual participam os filósofos do Círculo de Viena. O texto da comunicação apresentada consta no cap. IV da organização Estudos (1949), sob o título: Crítica preliminar ao conceito de fronteira epistemológica. Neste texto, o filósofo afirma a ineficácia da filosofia diante da tarefa de delimitar o espaço científico. Para ele, as ciências se dividem, sim, em diversas regiões, mas não caberia ao filósofo a marcação de suas fronteiras e sim aos próprios cientistas, em comunidade (BACHELARD, 2008, p.71).

Se houve uma mudança nos fundamentos que caracterizavam o discurso científico, a filosofia deveria buscar compreender estas transformações independentemente de seus pressupostos metafísicos. Há, em sua proposta, uma forte crítica a um tipo de filósofo dogmático que, para manter o edifício das suas convicções, não se dispõe a sair de sua zona de conforto, isto é, não se permite ir além daquilo que lhe é habitual, ou aparentemente apodítico. O que implica que, para a filosofia já não basta a conquista das verdades primeiras ou a percepção da habitual sequência dos fatos. É preciso tornar a filosofia tão dinâmica quanto o é o espírito científico.

Tal como toda e qualquer atividade humana, a ciência se faz no tempo presente. Ela não pode considerar seu passado como uma obra rara de museu, tampouco seu presente se inscreve em uma tabula rasa. A ciência, por ser uma ação do homem, é cultural e histórica. Essa foi uma das grandes contribuições do autor a que nos propomos estudar: reconhecer a descontinuidade no caráter histórico das ciências, sua capacidade de transformar-se no tempo por meio da retificação recorrente. O que só foi possível por meio do reconhecimento da positividade do erro nas ciências. Ou seja, a sua preocupação não é tanto com o conhecimento científico como resultado, mas com o processo que faz nascer e morrer saberes, com aquilo que nos permite reconhecer avanços na história da ciência. Este progresso só pode ser reconhecido por meio dos pontos de ruptura na história das ciências. Somente a partir de acontecimentos que rompem com o fluxo contínuo da temporalidade é que a ciência se faz mover na história. Estes "rompantes" serão vistos por nosso autor de maneira positiva: o erro se impõe e é em uma reação contra ele que a ciência se faz. A ciência é, afirma Bachelard, uma dinâmica de retificações. 
Roberto Torretti, filósofo chileno, diferencia dois tipos de rupturas na obra bachelardiana (TORRETTI, 2013, p.27-28). A primeira, ou primordial, diz respeito à separação entre conhecimento científico e senso comum, o que para Torretti corresponde à principal distinção entre a filosofia de Bachelard e as teorias do conhecimento precedentes. A segunda, consiste em uma troca conceitual e acarreta uma inovação imprevisível no modo de delimitar e enquadrar os fenômenos físicos. Essa ruptura não corresponde a uma completa destruição do passado. Na realidade, "só se destrói um livro de ciência contradizendo-o primeiramente e ultrapassando-o depois" (BACHELARD, 1990, p.14). Não é necessário que se queime Alexandria, mesmo porque, em tempos como o nosso, isso já não seria possível, o esquecimento de um saber se dá por meio de sua superação.

Estes instantes recebem também o nome de cortes epistemológicos. Ocorre um corte no curso contínuo do tempo tanto entre o conhecimento comum e o conhecimento científico, quanto de um determinado saber científico para outro. As regiões, ou cantões, de cientificidade constituem a afirmação da especialização como mais uma característica positiva das ciências do século XX para Bachelard. Há uma afirmação da coerência existente na pluralidade dos saberes em regiões distintas. Dentro de uma grande região como a Física, por exemplo, podemos observar uma primeira divisão entre a física teórica e a física experimental, além de outras divisões como a mecânica clássica, a mecânica quântica, a termodinâmica, o eletromagnetismo, a teoria da relatividade e a física nuclear.

"Ser um químico é colocar-se numa situação cultural, ocupando um lugar, incluindo-se numa categoria, numa cidade científica nitidamente determinada pela modernidade da investigação. Todo indivíduo é um anacronismo" (BACHELARD, 1990, p.11). Para Bachelard ser um cientista, a partir da modernidade, pressupõe uma formação e uma prática comuns a um grupo determinado. A história das ciências não resulta apenas, portanto, da genialidade de indivíduos, pois cada cientista, seja ele um Einstein ou um estudante, constitui uma parte do todo que é a comunidade científica. Neste sentido, a especialização que orienta a cidade científica é também aquilo que nos impede de pensar a cidade científica anterior ou alijada a aspectos sociais, uma vez que a atividade científica só se faz a partir de e para uma comunidade.

Diante disso, investigaremos a preocupação pedagógica presente nas obras de Bachelard, pois acreditamos que a educação, para além de ser um pressuposto para a formação da cidade científica, é uma atitude ético-política. A formação científica, neste sentido, comporta valores que deveriam ultrapassar os limites da reprodução de problemas matemáticos. Sua aposta na educação aparece de maneira transversal em muitas de suas publicações sobre as ciências, mas em A formação do espírito científico se pode notar que o assunto domina a obra que trata dos obstáculos epistemológicos.

A questão da educação nos parece ser o melhor caminho para entendermos uma possível proposta ética no pensamento bachelardiano. Apesar de não ser a questão principal, uma vez que a objetividade e o progresso científico constituem seu principal objeto, há uma aposta na educação em todos os seus argumentos acerca da necessidade de uma abertura da razão. Destarte, discutiremos no presente artigo se existe, por que e quais as consequências de uma possível anemia política na epistemologia bachelardiana. Analisaremos também como Bachelard aborda a questão da técnica e de que forma seu posicionamento em relação a ela contribuiu para que pensadores contemporâneos, sobretudo os representantes dos Science Studies, construíssem uma visão negativa sobre seu trabalho. Com isso, queremos refutar a ideia de que a epistemologia de Gaston Bachelard seja um pensamento datado ou limitado a manuais de história da filosofia, e afirmar que ainda é possível fazer por meio dela uma leitura crítica e profícua das ciências hoje.

\section{Há uma anemia política na epistemologia histórica de Bachelard?}

Ao apresentar o desenvolvimento das ciências nos séculos XIX e XX, ${ }^{2}$ Bachelard expõe a necessidade de a filosofia das ciências se reinventar em consonância com o processo criador dinâmico da atividade científica. A epistemologia bachelardiana sustenta, assim, a tese de que a filosofia das ciências deve atualizar sua linguagem

2 As teorias da relatividade e quântica, a especialização das ciências e a produção de fenômenos em laboratório, por exemplo. 
para alcançar as inovações científicas. A normatividade do pensamento bachelardiano se dirige, portanto, aos filósofos. Isso se mostra, sobretudo, quando da valorização do caráter matemático da "nova" física. Esta valorização supera por vezes suas considerações acerca do aspecto técnico dos objetos científicos. Sua definição de ciência, isto é, a Fenomenotécnica, "para além de significar a construção dos objetos em laboratórios, figura no pensamento bachelardiano como a própria atividade de conceitualização" (TORRETTI, 2013, p.59).

A matematização das ciências é apontada como a causa da especialização e, consequentemente, do progresso das ciências. No início do século passado, Bachelard defendia a positividade da especialização, por entender que o edifício da ciência não era homogêneo e que a prática do cientista era localizada e dinâmica, pois seu movimento era contínuo (BACHELARD, 1967, p.26). Como consequência da especialização, crescem a exigência de uma formação cada vez mais específica e a valorização de experimentos que demandam investimentos maiores, como acontece hoje em dia na chamada Big Science. Com isso, a atividade científica passa a servir a um determinado grupo de interesses e interessados bem específicos por depender cada vez mais de financiamentos públicos e privados. Isto - a matematização das ciências - foi visto por Bachelard não como um problema para o progresso das ciências, mas como o seu verdadeiro motor. A ciência, para Bachelard, não pode ser condenada em termos abstratos, pois ela é construída por e para os homens e, por isso, está sujeita também aos valores morais que estes defendem. Em resumo, Bachelard defende que a vocação científica não deve ser responsabilizada pela perversão dos valores humanos. Responsabilizar as ciências por crimes e crueldades cometidos por meio delas é, para ele, o mesmo que condenar uma faca e não o assassino na cena de um crime (BACHELARD, 1967, p.17).

Sua defesa forte das matemáticas, como parte imprescindível da nova física, faz com que o público leigo, o senso comum, seja alijado das discussões científicas. À primeira vista, entendemos que, para Bachelard, somente aqueles que tiveram formação para as ciências e dedicam suas vidas à construção do saber científico, têm voz na, por assim dizer, Ágora das ciências. Como se a epistemologia bachelardiana propusesse, com isso, uma demarcação entre ciência e sociedade. Ora, não concordamos com esta crítica tal como ela se expõe, pois, nosso autor não sugere em seus livros um método a ser seguido pelo cientista. Sim, é afirmado por ele que o saber científico não surge, continuamente, do senso comum, mas esta ruptura não corresponde a uma cisão entre ciência e sociedade, uma vez que não é possível pensar aquela fora dos limites desta. Suas reflexões, ao contrário, partem de uma reflexão crítica sobre os acontecimentos que marcaram a história do conhecimento. É a partir de uma análise recorrente que ele aponta momentos de ruptura, como, por exemplo, o que ocorreu na física entre os séculos XVII e XVIII, quando se intensifica o uso das matemáticas, sobretudo a partir da publicação da Philosophiae Naturalis Principia Mathematica de Isaac Newton, em 1687. Nesse sentido, a epistemologia bachelardiana analisa um acontecimento histórico em uma região da cidade científica. Ela reflete sobre o espírito de uma época, a atualização de uma ciência que, devido à sua forte matematização, mostrava-se cada vez mais regional, mais especializada.

Deste modo, a cidade científica era determinada por uma formação específica e por um ethos (uma atitude compartilhada), dos quais o filósofo, dedicado a compreendê-la, deveria aproximar-se sem, contudo, ser capaz de participar ativamente de suas discussões. O destino da epistemologia, enquanto disciplina, é o da análise dos resultados verificados na história das ciências. Neste sentido, concordamos com Yves Gingras, pois, se é verdade que o espírito científico é formado por meio de uma reforma na base das ciências, deve ser acrescentado que isto também afeta a estrutura da cidade científica e de suas condições de acesso (GINGRAS, 2001, p.119). A segregação entre ciência e conhecimento comum se torna ainda mais aparente, mas Bachelard defende a especialização e a dificuldade de acesso por ela criada. Sua defesa atenta para a necessidade de que a ciência precisa se complexificar, tornar-se difícil, criar problemas, para manter-se em ação (BACHELARD, 1990, p.249).

Aqueles que não quisessem ou não pudessem ultrapassar as dificuldades impostas pela especialização estariam, consequentemente, colocados à parte da cultura científica. A cidade científica, tal como descrita por Bachelard, exige uma formação e uma atitude comum a seus membros. O ethos da comunidade científica também resume os valores compartilhados por seus participantes, mas essa é uma das lacunas na epistemologia bachelardiana, que termina por não definir estritamente quais seriam as bases que regem o 
comportamento dos cientistas. Em uma análise crítica de seus textos, suspeitamos que ele não o faça por receio de sua descrição ser confundida com uma prescrição. Isso, contudo, limita nossas possibilidades de uma análise mais apropriada sobre a própria compreensão de Bachelard sobre as ciências, uma vez que ele opta por tratar de um modo superficial as questões que dizem respeito ao contexto da descoberta ${ }^{3}$. Devido a essa lacuna e à falta de estudos posteriores que tratem dessa questão, qual seja a de encontrar uma solução para o que parece ser um isolamento entre ciência e política, optamos por confrontar sua bibliografia com uma literatura que nos é contemporânea, a saber, os science studies.

A matematização das ciências e a valorização do erro foram amplamente discutidas na epistemologia histórica como um caminho para a objetividade e como o próprio motor das ciências, mas não foi problematizada a consequente exclusão do público em geral decorrente da especialização. Deste modo, se era possível, ou não, manter a sociedade como participante ativa da comunidade científica não constituía um problema a ser superado pela epistemologia bachelardiana. Essa postura diante das ciências, de uma não problematização das questões políticas e sociais exotéricas a elas, é o que leva o pensamento bachelardiano a receber críticas negativas. Isto se dá mesmo quando, por exemplo, da análise de problemas que extrapolam a formação científica pelo filósofo de $O$ materialismo racional:

A química é atualmente uma ciência "aberta" em que a problemática prolifera. Este futuro é grave. Chegou-se a um ponto da história em que o futuro da química compromete o futuro do gênero humano, tão grande é a verdade do destino do homem estar ligado aos seus pensamentos. Pela química e pela física nuclear, o homem adquire inesperados meios de potência, meios positivos que ultrapassam todos os devaneios de potência do filósofo. O materialismo erudito, que não é apenas uma filosofia especulativa, arma uma vontade de potência, vontade que se excita pela potência mesma dos meios oferecidos. Parece que, também no plano psicológico, a vontade de potência conhece uma reação em cadeia. Quanto mais se pode, mais se quer. Quanto mais se quer, mais se pode. Enquanto a vontade de potência era ingênua, enquanto era filosófica, enquanto era nietzschiana, não era eficaz - tanto para o bem como para o mal - senão à escala individual. Nietzsche agia sobre os seus leitores; um leitor nietzschiano que se torna autor tem apenas uma ação irrisória. Mas, desde que o homem se apodera efetivamente das potências da matéria, quando já não sonha com elementos intangíveis e afins [atomes crochus], mas organiza realmente novos corpos e administra forças reais, ele chega à vontade de potência dotada de uma verificação objetiva. Transforma-se num mágico verídico, demônio positivo (BACHELARD, 1990, p.11).

Nesta passagem, Bachelard compara a noção de vontade de potência filosófica, nietzschiana, a uma vontade de potência científica para explicitar sua ideia, qual seja a de que há uma superioridade da última em relação à primeira. Este posicionamento resume o seu otimismo em relação ao saber científico. Para ele, o cientista é capaz de produzir filosofia e não o contrário. Mais do que isso, Bachelard subestima a influência que uma filosofia, no caso a de Nietzsche, possa ter sobre o futuro da humanidade quando comparada à preponderância do sucesso científico. A filosofia é, em sua visão, quando tomada em si mesma, um pensamento estéril, pois não se observa, claramente, um progresso em sua historicidade. De modo que, quando comparadas, as teorias filosóficas não podem ser consideradas melhores que as outras ou mais próximas à verdade. Em resumo, para Bachelard não há rupturas na história do conhecimento filosófico que denotem um progresso, uma evolução, mas apenas ações localizadas, ou seja, uma interferência direta entre os seus leitores. Assim, para o filósofo francês, não é possível falar em progresso na filosofia do mesmo modo como nas ciências naturais, pois ele acredita que o produto do filósofo não tem força suficiente para

3 Tomamos aqui emprestado o termo "contexto de descoberta" do filósofo Hans Reichenbach, pois sua diferenciação entre contextos da descoberta e da justificação é bem próxima à proposta bachelardiana de uma psicanálise do conhecimento objetivo. Onde é também proposta uma separação entre as questões psicológicas, sociais, políticas e econômicas das questões relativas aos fatos científicos. 
modificar consideravelmente o futuro da humanidade. Seu posicionamento diante da filosofia reafirma sempre uma descontinuidade entre a cultura das ciências humanas e a cultura científica. Deste modo, entendemos que há um forte pessimismo no pensamento bachelardiano em relação à filosofia, que o faz ser pouco crítico em relação à sua própria prática enquanto filósofo e mesmo à prática científica. Uma das consequências disso foi ter seu trabalho filosófico também condenado por muitos, sobretudo por parte da filosofia analítica, ao esquecimento.

A história das ciências, tal como é usada em suas obras epistemológicas, isto é, como um instrumento para a filosofia, aponta sempre para uma comparação entre um período pré-científico e a ascensão de um novo espírito científico. Ou seja, uma história comparada que atenta sobretudo para os momentos em que a ciência se mostra, por assim dizer, próspera. Por isso, entendemos as críticas feitas à epistemologia de Bachelard, devido à sua negligência para com a história das ciências. Ao localizar os momentos de ruptura a partir do conhecimento de teorias, como a da teoria da relatividade e quântica, Bachelard acaba por, paradoxalmente, recorrer à historiografia whig ${ }^{4}$ para contrapor-se ao continuísmo histórico 5 .

Isto, para nós, constitui um paradoxo, pois a epistemologia bachelardiana ao mesmo tempo em que afirma a positividade da especialização, ela também esclarece a positividade do erro no progresso da história das ciências. Ou seja, mesmo quando da defesa de um progresso descontínuo, nosso autor reafirma a ideia de que a ciência tem em sua história as marcas dos vencedores, que se caracteriza pelo modo como ele expõe o jogo dialético entre as teorias. Por isso, pensadores contemporâneos condenam toda a filosofia de Bachelard ao ostracismo, por ele não ter uma perspectiva das ciências em sua relação com a sociedade e, principalmente, por ele não fazer uma história das ciências mais próxima da prática. Peter Galison, físico, epistemólogo e historiador da ciência, um dos que pensam criticamente essa historiografia, propõe uma alternativa a essa posição:

Cada vez mais, a todos os níveis - filosófico, histórico e sociológico -, menos sentido fazia para mim dividir a história da Ciência inteiramente de acordo com a teoria dominante nessa altura. Em vez de periodizar a história da Física por pontos de ruptura puramente ditados pela teoria (1900: descontinuidade quântica; 1905: relatividade especial; 1915: relatividade geral; 1925: mecânica quântica; 1947: eletrodinâmica quântica; etc.), comecei a trabalhar em termos de uma imagem tripartida, na qual a instrumentação, a experiência e a teorização caminhavam cada uma delas ao seu próprio ritmo. Uma tal imagem parecia oferecer uma epistemologia histórica (pedindo a expressão emprestada a Lorraine Daston e a lan Hacking) que entrava simultaneamente em conflito com uma história positivista que colocava a experiência no fundamento das ciências e com uma história anti-positivista que fazia da teoria a base destas (GALISON, 1997, p.397).

A proposta de autores como os que citamos dos Science Studies nos parece ser a de não limitar os estudos sobre ciências à investigação de uma única disciplina acadêmica. Não há mais necessidade de a Filosofia das ciências dedicar-se à sua autonomia, uma vez que esta, enquanto disciplina, já se encontra institucionalizada. Para entender as críticas ao pensamento bachelardiano, optamos por apresentar a seguir uma leitura comparada da obra de Bachelard e dos Science Studies. Interessa-nos fazer esta análise a fim de esclarecermos a ausência ou a função sócio-política da epistemologia francesa a partir dos pontos de ruptura e aproximação com estudos sobre ciências contemporâneos.

4 "Esse termo foi cunhado em 1931 por Herbert Butterfield. Ao inventá-lo, pretendia Butterfield combatê-lo como sendo o pecado mais mortal que um historiador poderia cometer. Sua condenação da história whig deve-se ao fato de que ela é presentista, atendo-se somente à apresentação dos momentos históricos em que a ciência foi vencedora. Uma outra possibilidade de caracterizar a história de tipo whig é como uma ratificação, quando não glorificação, do presente" (VIDEIRA, 2007, p.141-142).

5 Ver: BACHELARD, 1990, p.244. 


\section{Bachelard e Science Studies: Uma leitura comparada}

Diferentemente da epistemologia bachelardiana, os Science Studies entendem que para compreender a prática científica é preciso uma análise integrada a partir das perspectivas histórica, filosófica e sociológica das ciências. Um ponto em comum entre os Science Studies e Bachelard é o da afirmação de que as ciências trabalham localmente (racionalismo regional) e, por isso, deve-se buscar uma história local que acompanhe o dinamismo das ciências. Peter Galison entende - de maneira semelhante ao modo como Bachelard falava em retificações conceituais das quais a filosofia deveria acompanhar - que "as linguagens não podem, pura e simplesmente, ser consideradas como globais: elas estão permanentemente, de uma forma local, em fluxo, e essas alterações desenrolaram-se na História" (GALISON, 1997, p.398). E isto não se dá apenas entre conceitos de teorias distintas, como é no caso da mecânica de Newton e a relatividade de Einstein, mas também na linguagem usada, por exemplo, por trabalhadores da matemática pura e da matemática aplicada (GALISON, 1997, p.400).

Para Bachelard, a linguagem científica é local e dinâmica porque precisa acompanhar a construção dos objetos científicos. O epistemólogo francês percebeu isso e propôs que deveríamos ler a ciência contemporânea como fenomenotécnica, ou seja, como produção racional e técnica de fenômenos. Bruno Latour também afirmou que, para ser reconhecível, "o mundo precisará tornar-se um laboratório" (LATOUR; WOOLGAR, 1997). Essa aposta na produção dos fenômenos e dos fatos científicos pode ser apresentada como uma evidente aproximação entre as ideias desses pensadores. Para Latour e Woolgar, tanto a natureza quanto a sociedade devem ser explicadas pelos mesmos termos, isto é, de maneira simétrica. Eles propõem, com isso, uma antropologia das ciências que considere com igual importância os vencedores e os vencidos da história tanto a partir de seu contexto social quanto de seu conteúdo científico. Em seguida, essa proposta é radicalizada na Teoria Ator-Rede que defende uma análise simétrica total entre humanos e não humanos. Entretanto, ao defender a noção de simetria como formadora da base moral da obra $A$ vida de Laboratório (1979) e da base epistemológica da autonomia científica, Latour (e Steve Woolgar) pretende opor suas ideias às rupturas epistêmicas e às descontinuidades históricas, conceitos-chave da proposta de Bachelard. Em suas palavras:

Em Formação do espírito científico, Bachelard não cessava de ridicularizar os pseudo-sábios do século XVII para opô-los à ciência correta, ou pelo menos em constante retificação. Bloor, em Socio/logie de la logique, esforça-se, ao contrário, para restabelecer uma simetria total de tratamento entre os vencidos da história das ciências e os vencedores, esses famosos retificadores e revolucionários sempre bramindo a guilhotina do corte epistemológico (LATOUR e WOOLGAR, 1997, p.23).

Essa discordância é de fato sustentada nas obras bachelardianas, ou Latour teria se precipitado ao contrapor de maneira absoluta, em sentido forte, as noções de simetria e ruptura? Uma vez que a noção de objetividade bachelardiana é construída por aproximação, formação, o erro que provocou a retificação e instaurou a ruptura acaba por incorporar-se às diversas determinações do real. De outra forma, o que está em jogo na defesa dos science studies quanto à noção de simetria se refere à defesa e à explanação de que há uma área de interação entre ciência e sociedade. O modo pelo qual isso é proposto nega em princípio uma justificação filosófica da ciência anterior aos estudos empíricos sobre as suas práticas reais. Enquanto a epistemologia de Bachelard legitimava a ciência por meio de relatórios produzidos pelos próprios cientistas, o que ocasiona um eterno atraso da filosofia para com a ciência, Latour sugere os estudos etnográficos, as pesquisas de campo, a fim de diminuir a distância entre as ciências ditas hard e soft. Os estudos etnográficos representam, portanto, uma tentativa de apreender a ciência em seus próprios termos, tal como ela se faz, e exigiriam essa leitura simétrica. Contudo, é preciso compreender também que para uma análise filosófica da história das ciências, tal como pretendia a epistemologia histórica de Bachelard, o conceito de ruptura não poderia ser descartado. Isto ficará mais claro quando da nossa exposição sobre a educação no pensamento bachelardiano. 
A despeito disso, concordamos com Latour quando ele afirma haver uma história dos vencedores na prescrição filosófica bachelardiana. Ainda que alguns autores dos Science Studies, como Ian Hacking em Representar e Intervir (1983), trabalhem com uma clara distinção entre ciências humanas e ciências naturais, a filosofia e as ciências não são forças contrárias, mas constituem modos complementares de compreender a complexidade inerente à atividade científica. Por isso, filosofia, história e antropologia contribuem, em diversos aspectos, para os estudos sobre as ciências. Nesta perspectiva, a filosofia das ciências não perde sua importância, mas a preocupação com sua autonomia enquanto disciplina é, como já mencionamos, deixada de lado. Não que o filósofo perca com isso seu expediente, mas ele deverá orientar seu trabalho para além da teoria, a fim de que instrumentação e experiência sejam também analisadas.

É preciso ressaltar também que a filosofia do novo espírito científico, que afirma a positividade do erro como verdadeiro motor da própria história das ciências, não foi capaz de antever o pessimismo da sociedade frente a uma ciência desconectada da sociedade. Sobretudo no período pós-Segunda Guerra, quando a ciência passa a ser vista com certa desconfiança por todos os que viam nela a força nascente da rosa radioativa. Como manter o discurso de que a ciência deve seguir livre e autônoma, em sua própria cidade, quando a sociedade está desde o início imbricada nos meandros da comunidade científica? Bachelard escreve sua epistemologia entre os anos de 1928 e 1953, isto é, o faz no período em que essas questões ainda estão se consolidando; ao passo que Latour contempla os fatos já nos finais do século XX e início do XXI. Essa distância temporal em relação ao problema parece ter exercido grande influência nas respostas de ambos. Mas buscaremos mais provas nos escritos bachelardianos antes de apontarmos nossas conclusões.

Bachelard escreve em um contexto histórico no qual a filosofia das ciências é uma disciplina relativamente jovem no corpo institucional da academia francesa ${ }^{6}$. Por isso, entendemos a sua preocupação em demarcar as funções e prioridades do trabalho filosófico nas ciências, sobretudo em sua função pedagógica. A epistemologia bachelardiana propõe, diante da crescente necessidade de uma formação científica especializada, uma atitude diferente do filósofo: uma vida de estudante. Caberia ao epistemólogo assumir sempre a postura de aluno diante do cientista. A educação é, aliás, uma preocupação recorrente nas obras bachelardianas.

\section{A educação como projeto ético-político}

Em A formação do espírito científico, obra em que nosso autor se dedica ao estudo dos obstáculos epistemológicos, a questão do ensino e aprendizado de ciências na educação básica é objeto de discussão, mas encontraremos a pedagogia, ainda que como um tema transversal, na maioria de seus textos. A educação formal, para Bachelard, deveria instigar a curiosidade e a vocação para as ciências e não promover a repetição do mesmo. Em suas palavras:

Tem-se repugnância em violentar o "senso comum". E, nos métodos de ensino elementar, adiam-se de ânimo leve os tempos de iniciações viris, procura conservar a tradição da ciência elementar, da ciência fácil; considera-se um dever fazer que o estudante participe da imobilidade do conhecimento inicial. É necessário, apesar disso, conseguir criticar a cultura elementar. Entra-se, então, no reino da cultura científica difícil (BACHELARD, 1990, p.244).

Bachelard foi professor de física e química no Collège de Bar-sur-Aube, entre os anos de 1919 e 1930, e só se licenciou em filosofia nos anos vinte do século passado. Seu interesse pelas ciências naturais o levou a pensar na educação básica e em sua relação com o progresso científico. Deste modo, encontra-se em Bachelard uma filosofia preocupada com a formação de todos os alunos para as ciências. Não se trata da defesa de

6 Bachelard foi, entre os anos 1940 e 1955, professor de História e Filosofia das Ciências na Sorbonne e diretor do Instituto de História das Ciências e das Técnicas fundado pela Universidade de Paris apenas em 1932. Sobre isso ver: BRENNER, Anastasios. Les origenes françaises de la philosophie des sciences. Paris: PUF, 2003. 
uma educação puramente técnica pela qual todo e qualquer aluno deveria ser formado para trabalhar para as ciências, mas, ao contrário, de uma formação que exortasse ao novo espírito científico.

\begin{abstract}
Nós que tentamos extrair as novas maneiras de pensar, devemos dirigir-nos para as estruturas mais complicadas. Devemos aproveitar todos os ensinamentos da ciência, por muito especiais que sejam, para determinar as novas estruturas espirituais. Devemos compreender que a aquisição de uma forma de conhecimento se traduz automaticamente numa reforma do espírito. É, pois, necessário dirigir as nossas investigações no sentido de uma nova pedagogia (BACHELARD, 1978, p.77. Grifo nosso).
\end{abstract}

Bachelard critica o modo pelo qual os manuais didáticos da época expõem as ciências: como um conjunto de regras a ser decorado e aplicado. Esta crítica nos parece bastante atual, de modo que o ensino básico brasileiro também exige do aluno a capacidade de repetir fórmulas e soluções previamente dadas visando a aprovações em avaliações periódicas e ao exame para ingresso ao ensino superior. O discente, inserido neste modelo, acaba por não ver as ciências naturais como um ambiente de pesquisa e produção de saber e, consequentemente, também não é estimulado a ir além daquilo que já se encontra dado nos livros didáticos. As fórmulas são reproduzidas sem qualquer preocupação com os sistemas de pensamento que elas corroboram. Do mesmo modo, Bachelard alertava que esse distanciamento entre o ensino e a atualidade das ciências sinalizava um atraso para ambos:

Não é fácil captar de imediato o sentido desta tese, porque a educação científica elementar costuma, em nossa época, interpor entre a Natureza e o observador livros muito corretos, muito bem apresentados. Os livros de física, que há meio século são cuidadosamente copiados uns dos outros, fornecem aos alunos uma ciência socializada, imóvel, que, graças à estranha persistência do programa dos exames universitários, chega a passar como natural; mas não é; já não é natural. Já não é a ciência da rua e do campo. É uma ciência elaborada num mau laboratório, mas que traz assim mesmo a feliz marca desse laboratório. Às vezes, trata-se do setor da cidade que fornece a energia elétrica e que vem, assim, trazer os fenômenos dessa antiphysis na qual Berthelot reconhecia o sinal dos novos tempos (Cinquantenaire scientifique, p. 77); as experiências e os livros agora estão, pois, de certa forma desligados das observações primeiras (BACHELARD, 1996, p.30).

A crítica bachelardiana, neste sentido, se dirige à falta de incentivo para uma formação que permita ao aluno ser capaz de ir além da reprodução e da perfeita aplicação de fórmulas e teorias datadas. Com isso, ele busca uma reforma desde os anos iniciais da educação até a própria formação científica e acadêmica. Para isso, ele se utiliza da leitura da obra de Alfred Korzybski, Science and Sanity, An introduction to non-aristotelian systems and general semantics (KORZYBSKI, 1933). Esta obra sugere uma reforma não-aristotélica de diversas ciências, inclusive a pedagogia. Korzybski considera o cérebro da criança como um domínio inacabado e não desocupado, isto é, como um organismo aberto, um organismo das funções psíquicas abertas, que vai ser acabado por meio da linguagem, da educação, da instrução. Esta educação exige uma experiência de abertura em que o mestre deve aprender ensinando (BACHELARD, 1978, p.78), isto é, tanto o professor quanto o aluno são sujeitos ativos na educação.

Bachelard concorda com Korzybski, no que tange à ideia de uma educação aberta e dinâmica, uma educação não-escolástica, por acreditar que somente assim a educação formal seria capaz de instruir sujeitos suficientemente criativos e, ao mesmo tempo, comprometidos tal como as ciências contemporâneas exigem. Os comentários de Bachelard sobre a educação formal nos sugerem não apenas um posicionamento efetivamente político, como também uma proposta ética com produção de cultura, isto é, comportamentos, interesses e valores próprios à cidade científica ${ }^{7}$. Há em suas proposições pedagógicas uma inclinação para o incentivo de

7 Não queremos dizer aqui que as ciências naturais, tal como apresentadas por Bachelard, se aproximariam de um modelo de Filosofia da Natureza, como o que se constituiu desde a Antiguidade. Haveria uma incompatibilidade sobretudo em relação 
valores, como a coragem e a criatividade, que nos permitem sugerir que a acusação de uma completa anemia política não condiz com a complexidade do pensamento bachelardiano. Defender uma reforma na educação básica constitui, para nós, não apenas um forte posicionamento político, mas também revolucionário.

Em julho de 2012, ocorreu em Cerisy, na França, um encontro dedicado a Bachelard, intitulado: "Gaston Bachelard, science, poésie, une nouvelle éthique?". Diferentes filósofos, especialistas ou não no pensamento bachelardiano, propuseram uma leitura ética das questões epistemológicas e poéticas colocadas por nosso autor. O resultado deste colóquio foi publicado no ano seguinte em uma organização de textos apresentados e introduzidos por Jean-Jacques Wunenburger e Jean-Philippe Pierron, que resumem o problema central do encontro:

Para além dessas relações entre Ciência e poesia, entre teorema e poema, poder-se-ia encontrar também, em filigrana, as linhas profundas de uma filosofia prática, de um humanismo e de uma sabedoria? Porque Bachelard fala tanto do desejo e da vontade, da criança e do adulto, do lazer e do trabalho, do amor e do confronto, da autoridade e da revolta, da solidão e da comunidade, da liberdade e da necessidade, da vida e da morte, etc.; quanto de entradas, condensadas em certas passagens ou dispersas na obra, em uma filosofia do bem viver e do bem-estar junto [bien-être ensemble]. Ele ressalta uma imagem do homem a realizar, em si mesmo, mas também com os outros, que abre sobre as ideias educativas, éticas e mesmo políticas (WUNENBURGER; PIERRON, 2013, p.11).

Vincent Bontems, em um artigo nesta coleção, também atenta para o fato de que, apesar de não ser uma questão evidente em seus textos, a proposta do surracionalismo, isto é, de uma ciência constantemente aberta ao novo, "responde, de início, a uma exigência ética" (BONTEMS In: WUNENBURGE; PIERRON, 2013, p.379). Esse racionalismo aberto é descrito por Bachelard como a própria capacidade das ciências de renovar e transformar suas bases a partir de novas experiências e hipóteses. Esta abertura, assinala Bontems, corresponde a uma obrigação tanto de ordem ética quanto epistemológica, pois compreende tanto imperativos ligados à eficácia científica quanto valores, tais como a lucidez e a honestidade intelectual (BONTEMS In: WUNENBURGE; PIERRON, 2013, p.384). De outro modo, Frédéric Worms, em um trabalho na mesma obra, intitulado Le foyer moral de la philosophie de Bachelard, vai buscar nos textos da poética uma forma de tornar evidente a questão moral na filosofia bachelardiana. A questão dos valores morais na epistemologia bachelardiana é, de fato, problemática. Sobre isso, Cristina Chimisso também escreve:

As razões pelas quais Bachelard tem que atribuir um importante papel para a ciência são, penso eu, de duas ordens. A primeira é simplesmente histórica. A epistemologia de Bachelard é histórica, e os resultados da observação das formas históricas de que tomou conhecimento. Em outras palavras, para ele a humanidade, em sua história, tem exercido a racionalidade através da ciência, e o papel das epistemologias é analisar essas formas, tomando como sua norma a forma historicamente mais avançada. As outras razões pelas quais Bachelard valoriza a ciência acima de qualquer outro tipo de atividade social pertencem à ética [...] Para Bachelard a ciência deveria ser escolhida, pois, em sua opinião, permite aos seres humanos superar suas unidades egoísta, individualista e emocional e a entrar em um mundo de objetividade e trabalho. A história da ciência para ele é uma história de progressiva socialização, e o objetivo da ciência na objetividade assegura que o "egoísmo" não pode ter lugar nela. Ele pensa que a missão do historiador da ciência deveria ser mostrar "o valor profundamente humano da ciência corrente" (Bachelard, 1972a, p. 152) [...] Os valores morais foram o que o fez escolher a ciência como guia para a filosofa e a vida social (CHIMISSO, 2008, p.391).

à "crescente especialização e profissionalismo das ciências modernas" diante da "incorporação das ciências, sobretudo a Medicina, ao sistema cultural da Antiguidade" (JAEGER, Werner. Paideia: a formação do homem grego. $5^{\text {a }}$ ed., São Paulo: Martins Fontes, 2010, p.1001-1002). 
Chimisso defende, com isso, que há um forte posicionamento ético na separação entre saber científico e saber pré-científico, porque o primeiro seria capaz de ir além dos interesses individuais, egoístas, em função de uma objetividade, de uma progressiva socialização. Ela entende que Bachelard tenha valorizado as ciências devido à capacidade de desenvolvimento e preservação dos valores morais que elas pressupõem. Deste modo, analisaremos agora a partir da questão da técnica porque, para Bachelard, os valores morais pertinentes ao saber científico devem guiar outros aspectos da vida humana, como, inclusive, a educação formal, a sua formação.

\section{Ciência é técnica: Arte de fazer saber}

Bachelard faz uso do termo "técnica", como veremos, como pressuposto e produto da atividade científica. Não há uma obra inteiramente dedicada ao problema da técnica, mas ela constitui também uma questão transversal em todos os seus escritos sobre as ciências. Com isso, queremos dar continuidade a uma abordagem ético-política na epistemologia do não, por entendermos que possa haver aí um ponto pouco explorado na filosofia de Bachelard, tanto por sua complexidade quanto por seu caráter incompleto.

Mesmo antes dos anos vinte do século passado, mas sobretudo a partir deles, cientistas e filósofos tentaram compreender a importância da técnica para a história das ciências. Esta é, para nós, uma das principais contribuições de Bachelard para os estudos sobre ciências: a noção de fenomenotécnica. Ou seja, sua visão sobre a ciência moderna é, fundamentalmente, produção técnica de fenômenos, invenção de objetos no laboratório. A ciência se faz, se constitui, para Bachelard, somente quando da criação de seu objeto. Construtivismo e realismo deixam de ser metafísicas concorrentes na prática científica e, por isso, são conciliados na filosofia bachelardiana, que afirma a produção de fatos científicos originária de uma fenomenotécnica. Nos anos noventa do século XX, como já mencionamos, Latour confirma tal pensamento, ao concluir que, para ser reconhecível, o mundo precisará tornar-se um laboratório. Veremos agora de que forma a epistemologia bachelardiana chegou a essa conclusão e porque suas análises não atingiram a mesma complexidade das discussões geradas pela "tecnociência" de Latour.

Para Bachelard a técnica é uma atividade de produção de saberes constitutiva do próprio homem. É por ela que os objetos científicos são plenamente realizados. Trata-se, portanto, não apenas de um saber abstrato uma vez que a técnica está, para Bachelard, intimamente ligada à prática. Nota-se ainda que em sua obra o termo "técnica" aparece em diferentes situações e, em consequência disso, assume distintas funções em sua análise sobre as ciências. Ora ela representa um método, ora é usada como um instrumento, ou um critério de clareza, ou um valor de explicação e, na maioria das vezes, como a própria atividade científica. Fato para ele é que não há ciência sem técnica, e é a partir dela que ele afirma poder pensar em uma evolução na história da ciência.

É sempre em função de um avanço técnico, seja ele abstrato ou experimental, que a ciência é capaz de corrigir-se e progredir. Ao afirmar que a alquimia faz parte de um período pré-científico quando comparada à Química Moderna, Bachelard justifica sua asserção a partir da técnica disponível para os alquimistas e os cientistas modernos. De fato, ele não quer alijar a alquimia da história das ciências, mas sim situar o progresso técnico em curso. Por isso, ele afirma que a alquimia deve constar como um período pré-científico na história da Química: "No mínimo, é surpreendente que doutrinas tão fúteis consigam ter uma história tão longa, continuem a se propagar, mesmo com o desenrolar do progresso científico, até os dias de hoje" (BACHELARD, 1996, p.58).

A prática alquímica reúne em si uma ambivalência objetiva e subjetiva porque se utiliza da representação simbólica. Por isso, Bachelard afirma que antes de uma análise objetiva dos resultados experimentais da alquimia, deve-se julgá-la do ponto de vista subjetivo, isto é, por meio dos seus resultados morais. Para Bachelard, um livro alquímico é tanto um livro de moral quanto de ciência, por isso ele buscou provar em A formação do espírito científico que a alquimia pode ser uma cultura moral elevada (BACHELARD, 1996, p.232). Os valores morais são, na leitura bachelardiana, a base da alquimia. Logo, quando um alquimista não 
atinge seu objetivo em uma experiência, ainda que a justificativa se dê por um fracasso material, ele pode interpretar esta falha por aspectos subjetivos:

Quando uma experiência de alquimia não dá certo, a conclusão é apenas que não foi usada a matéria adequada, os germes exigidos, ou até que o tempo da produção ainda não chegou. Pode-se quase dizer que a experiência alquímica desenvolve-se numa duração bergsoniana, duração biológica e psicológica(...) Mas existe ainda um modo mais íntimo de interpretar o fracasso material de uma experiência alquímica. É questionar a pureza moral do experimentador. Não conseguir produzir o fenômeno esperado com apoio dos símbolos corretos não é um simples fracasso, é um déficit psicológico, é uma falta moral. É sinal de uma meditação superficial, de um descuido psicológico, de uma prece menos atenta e pouco fervorosa. Como disse com acerto Hitchcock em livros pouco conhecidos, nos trabalhos dos alquimistas existem menos manipulações e mais complicação (BACHELARD, 1996, p.62).

Deste modo, Bachelard afirma que "acima da interpretação materialista da alquimia, deve haver lugar para a psicanálise anagógica do alquimista” (BACHELARD, 1996, p.64). Uma análise que esclareça os aspectos subjetivos da alquimia a fim de produzir um relato objetivo da sua prática. Para Bachelard, esta ciência está muito mais implicada em um sistema de valores morais do que a Ciência Moderna (BACHELARD, 1996, p.233). A fenomenotécnica, a produção matemática e técnica de fenômenos, ao contrário, confere à atividade científica um grau de objetividade que escapa à produção alquímica. Por isso, o epistemólogo francês situa a técnica moderna e seu consecutivo progresso científico como uma fronteira em relação ao pensamento alquímico. O simbolismo presente no laboratório dos alquimistas reforça a tese bachelardiana de que há em seu esforço um subjetivismo que ultrapassa a objetividade científica, de tal modo que não se poderia esperar os mesmos resultados encontrados pela química moderna.

Jamais as qualidades de abnegação, probidade, paciência, método escrupuloso, trabalho persistente foram tão intimamente integradas ao ofício quanto na era da alquimia. Parece que, hoje, o pesquisador de laboratório consegue se afastar com mais facilidade de sua função. Ele não confunde a vida sentimental com a vida científica. $O$ laboratório não fica mais na própria casa, no sótão ou no porão. Ele o deixa à noite, como quem sai do escritório, e volta à mesa familiar onde o esperam outras preocupações, outras alegrias (BACHELARD, 1996, p.63).

Para Bachelard, o laboratório moderno é isolado da vida íntima, distanciado dos valores morais da vida comum, pois pressupõe uma técnica distinta, valores diferentes da dicotomia entre bem e mal. Aqui a técnica é entendida tanto como método quanto como instrumento. De modo que uma hipótese ou uma abstração matemática também são, na perspectiva bachelardiana, técnicas. Em resumo, a ciência moderna não pode ser vista dissociada da técnica. Muito se perde, aliás, quando da separação da técnica antiga (téchne) e da técnica moderna ${ }^{8}$. Cabe ressaltar, que a crítica encontrada na epistemologia bachelardiana que se refere à produção técnica industrial - que veremos em breve - não corresponde à sua total compreensão sobre o conceito. De modo que, na leitura bachelardiana das técnicas, seu otimismo frente ao progresso científico termina por mascarar os problemas relativos ao contexto sócio-político.

Bachelard já em sua tese de doutoramento, publicada em 1928, atenta para a força das técnicas nas ciências pura e aplicada. Não se pode negar a capacidade técnica da experimentação, tampouco nosso autor deixa de lado a importância da técnica no aspecto teórico. "O produto científico é um momento específico bem definido de uma técnica objetiva” (BACHELARD, 1996, p.143). Em rigor, ciência é para o filósofo francês técnica, isto é, produção de conhecimento objetivo por meio de uma técnica que se atualiza constantemente. 
Por isso, a alquimia é por ele analisada como um conhecimento pré-científico, pois não conseguiu alcançar o sucesso da técnica moderna. "Convém lembrar que a técnica moderna, a partir de uma base abstrata, conseguiu multiplicar os cheiros a tal ponto que o laboratório pode ser mais rico que o jardim!" (BACHELARD, 1996, p.147). Com isso, Bachelard quer afirmar a capacidade da ciência de produzir conhecimento técnico, a partir da produção de novos objetos, novos fenômenos, que "objetificam" e fomentam o sucesso da empresa científica. Neste sentido, sua preocupação mais uma vez se dirige à filosofia das ciências a fim de que o epistemólogo seja capaz de ir além das críticas superficiais à questão da técnica:

A propósito da descoberta da radioatividade artificial, Polard e Davidson insistem igualmente no desenvolvimento espantoso, "the astonishing development" do campo dos conhecimentos humanos. Desde 1933, afirmam eles, até 1945 (data da publicação do seu livro), o número dos radioelementos artificiais passou de 3 para 300. Esta proliferação extraordinária da ontologia materialista não pode, naturalmente, ser avaliada com justiça a partir do exterior. É por isso que o filósofo não se impressiona com este desenvolvimento espantoso. Ele lê e relê generalidades que condenam a técnica. Não presta qualquer atenção ao carácter eminentemente desinteressado de algumas investigações técnicas, não vê a sua beleza intelectual, permanece estranho à harmonia que se revela nesta multiplicidade de seres bem ordenados. Desumaniza, assim, um esforço prodigioso do espírito humano, o próprio esforço da cidade científica permanece um mundo a criar numa extraordinária novidade (BACHELARD, 1990, p.245).

O progresso científico alcançado por uma técnica cada vez mais especializada fez com que Bachelard rompesse de vez com o discurso filosófico que generaliza e condena a técnica ao culpá-la por alienação. Não há aqui apenas uma defesa cientificista da técnica, uma vez que o filósofo da fenomenotécnica distingue a técnica nas ciências e a técnica como instrumento e objeto da produção industrial:

A ciência enfrenta a irracionalidade fundamental do dado. Essa irracionalidade solicita continuamente a ciência, obriga-a sempre a um novo esforço. Já a indústria procura inscrever na matéria um racional claramente reconhecido, visto que desejado. De um lado, procura-se o racional, de outro, ele é imposto. Na técnica, o objetivo se integra realmente no ser que o realiza, é seu elemento principal e, desta feita, o "isto deve ser" não soa como presunção lógica, mas como ordem. O elemento descritivo deve portanto ceder a vez ao elemento normativo. É em segundo lugar que o juízo de conhecimento se apresenta; o juízo de valor o domina e, de certa maneira, o prepara (BACHELARD, 2004, p.161-162).

O interesse vital pela busca desinteressada é aquilo que, para Bachelard, diferencia as ciências da produção industrial. Enquanto aquela corresponde a uma técnica voltada para a produção do saber, esta se preocupa em produzir a partir de uma demanda, em função de interesses particulares. Deste modo, ciência e indústria constituíam técnicas distintas e por isso mereciam reflexões separadas, bem mais complexas que as generalizações filosóficas que condenavam a técnica em sua totalidade. A partir dessa distinção, o epistemólogo vai afirmar uma vez mais o caráter de ciência menos como objetiva e mais como projeto9. Esse otimismo por parte da epistemologia bachelardiana em relação ao progresso científico o impossibilitou de ver que há uma íntima relação entre as ciências, tanto a produzida na indústria quanto a que ele afirma ser realizada sem interesse - caso isso de fato exista -, e os interesses exotéricos a elas. Assim, concordamos com a seguinte crítica de Latour:

Seu "materialismo científico", segundo suas próprias palavras, era, na maior parte das vezes, a chave para distinguir a ciência das ideias "pré-científicas". Seu interesse exclusivo pelo "corte epistemológico" impediu-o de realizar uma pesquisa de natureza sociológica

9 Projeto tem o mesmo sentido de quando falávamos em progresso, isto é, que possui o caráter dinâmico e sempre aberto. 
sobre a ciência, embora muitas de suas observações sobre a ciência tenham peso maior quando colocadas em contexto sociológico (LATOUR e WOOLGAR, 1997, p.267).

Não era o objetivo da epistemologia bachelardiana efetuar uma pesquisa de natureza sociológica, o que nos aproxima das palavras de Latour, entretanto, faz-se necessário reconhecer as contribuições da fenomenotécnica para os estudos sociais das ciências. Ainda que Bachelard se mantenha preocupado com as rupturas epistêmicas, sua proposta da fenomenotécnica lançou nova luz sobre as discussões em filosofia das ciências e se mantém atual para os estudos sobre a técnica. Deste modo, entendemos que Latour use a ruptura bachelardiana como uma perspectiva contrária à sua proposta simétrica, tal como Bachelard o fez em sua filosofia do não com teorias do conhecimento que o precederam. Essa negação, contudo, aponta mais para um problema acerca da visão de história da ciência que Latour e Bachelard, de fato, não compartilham. Nas palavras de Latour:

Os pressupostos da sociologia do conhecimento jamais teriam intimidado por muito tempo os etnólogos se os epistemólogos não houvessem elevado a nível de princípio fundador esta mesma assimetria entre as verdadeiras ciências e as falsas. Apenas estas últimas - as ciências "proscritas" - podem estar ligadas ao contexto social. Quanto as ciências "sancionadas", apenas se tornam científicas porque separam-se de qualquer contexto, qualquer traço de contaminação, qualquer evidência primeira, chegando mesmo a escapar de seu próprio passado(...) Esta é a diferença, para Bachelard e seus discípulos, entre a história e a história das ciências. A primeira pode ser simétrica, mas isto não importa porque nunca trata da ciência; a segunda jamais deve ser simétrica, a fim de que o corte epistemológico permaneça total. (...)Só é científico aquilo que rompe para sempre com a ideologia. Se seguirmos tal princípio, é de fato difícil seguir os quase-objetos em seus princípios e fins. (...) O princípio de simetria reestabelece, pelo contrário, a continuidade, a historicidade e, vale lembrar, a justiça. Bloor é o anti-Canguilhem, da mesma forma que Serres é o anti-Bachelard. O que, por sinal, explica a total incompreensão, na França, tanto da sociologia das ciências quanto da antropologia de Serres (Bowker e Latour, 1987). "O único mito puro é a ideia de uma ciência purificada de qualquer mito", escreve este último ao romper com a epistemologia (Serres, 1974, p.2S9) (LATOUR, 1994, p.92-93).

Enquanto para Bachelard a fenomenotécnica é plenamente capaz de explicar a complexidade técnica que envolve a prática científica que lhe fora contemporânea, Latour vai lançar mão da tecnociência e da Teoria Ator-Rede para assentir que era preciso pensar a interface entre ciência e sociedade, a fim de compreender as questões imbricadas em ciência e tecnologia. O objetivo da epistemologia bachelardiana era o de descrever as ciências naturais e apontar os caminhos possíveis para a filosofia das ciências, quais sejam: o racionalismo aplicado e o materialismo racional. O fim da proposta do sociólogo das ciências nos parece ser - dada a leitura das obras Jamais fomos modernos e A vida de laboratório - o de possibilitar um diálogo interdisciplinar capaz de compreender as ciências em suas complexas relações com o contexto social. Enquanto Bachelard aceita os relatórios produzidos pelos próprios cientistas, Latour afirma que apenas pela etnografia seríamos capazes de ver a ciência em ação.

Assim, vemos que ambas as empresas são igualmente capazes em seus propósitos e que as críticas dirigidas à epistemologia bachelardiana são extremamente válidas, inclusive para a sua própria intelecção. Há em Jamais fomos modernos uma recusa do projeto de modernidade que é assimilado na epistemologia bachelardiana, quando esta defende uma separação clara entre natureza, ciência e sociedade. Com isso, a objetividade científica que já havia sido problematizada por Bachelard é agora colocada em xeque pela antropologia social latouriana, que afirma não ser possível separar as questões das ciências e das técnicas do seu contexto da descoberta.

A técnica, motivo de otimismo e medo em relação ao progresso das ciências, constitui um ponto de interesse em comum para Bachelard e Latour. De modo que temos, por exemplo, uma parte de A vida de 
laboratório dedicada a pensar a fenomenotécnica. Trata-se, para nós, de uma nova abordagem para o mesmo problema: a objetividade científica. O epistemólogo francês a coloca em termos de produção técnica a fim de defender a atividade científica da própria filosofia. Diante disto, o sociólogo francês questiona: "como a objetividade que não tem a sociedade por origem é produzida por essa sociedade?" (LATOUR; WOOLGAR, 1997, p.34). Esse problema, que também é o nosso, coloca em risco toda a proposta bachelardiana. Não nos interessa salvar ou não a filosofia do não do ostracismo, mas sim verificar se não há uma condenação apressada de sua epistemologia.

\section{0 pensamento bachelardiano para a Filosofia contemporânea}

A concepção de ciência moderna em Bachelard é, essencialmente, fenomenotécnica, i.e., "produção inteligente de fenômenos que os descreve e explica" (TORRETTI, 2012, p.97). Sobre este pensador e as críticas a ele dirigidas, no que se refere à história das ciências e à falta de diálogo com o social, Torretti o defende ao afirmar que a noção de fenomenotécnica está longe de ser uma coleção cumulativa de acertos das ciências (TORRETTI, 2012, p.99). Ainda que Torretti concorde que a epistemologia bachelardiana esclarece apenas os aspectos cognitivos da atividade científica, o filósofo chileno não aceita que, por isso, a história das ciências realizada por Bachelard seja apenas uma coleção de demonstrações empíricas e formais dos resultados científicos. Para ele, a reflexão bachelardiana, ainda que limitada a uma abordagem objetiva das ciências, foi capaz de afirmar a necessária relação entre teoria e observação, o que possibilitou a retificação das noções de objetividade e realidade (TORRETTI, 2012, p.101-102).

Para Torretti, a positividade do pensamento bachelardiano se encontra na sua capacidade de compreender a objetividade científica como o resultado do confronto da razão aplicada com a faculdade de sonhar. Este movimento, afirma Torretti (TORRETTI, 2012, p.101-102), se faz em uma ruptura com a faculdade da imaginação, por meio de uma outra faculdade criadora, a saber, a razão aplicada que produz (inventa) estruturas matemáticas. Este processo de produção, construção de saberes inspira e guia a realização fenomenotécnica. A objetividade assim analisada permanece como uma organização natural. Não queremos com isso dizer uma organização interna da natureza que nos conduza ao seu conhecimento, mas sim uma harmonia entre o dado e o método experimental, uma organização que justifique a necessária interseção entre observação e teoria.

Hans-Jörg Rheinberger, filósofo e bioquímico suíço, o desafio filosófico mais importante da epistemologia bachelardiana foi menos a sua postura construtivista radical e mais a sua defesa da fragmentação do conhecimento em regiões epistemológicas devido à especialização das ciências, notável à época (RHEINBERGER, 2005, p.323). Em consequência disso, a cidade - ou a comunidade - científica é a expressão social do processo de recorrência que caracteriza a aquisição de conhecimento científico no racionalismo aplicado. E sobre as críticas à epistemologia bachelardiana, ele pondera que Bachelard:

(...) foi criticado com o argumento de que privilegiou o conhecimento científico e de que trouxe em sua esteira todo o conjunto de valores da filosofia da ciência clássica com sua ênfase na verdade. Se a ciência fosse analisada de uma forma estritamente sócio-construtivista e entendida como um fenômeno social genuíno, então os filósofos da ciência teriam que dispensar epistemólogos como Bachelard. Talvez seja o momento para uma reavaliação. Inegavelmente, os escritos de Bachelard atestam ao longo de todo "progresso científico", no sentido de uma permanente ruptura com a experiência adquirida. Em 1949, no Congresso Internacional de Filosofia em Paris, Bachelard chegou ao ponto de dizer que "parece-me que a própria existência da ciência é definida como um progresso do conhecimento". Mas é crucial entender que "progresso" no sentido de Bachelard é menos um processo de perfeição ou uma abordagem gradual para um fim predeterminado do que um movimento constante, um contínuo, uma produção diferencial de novos conhecimentos (RHEINBERGER, 2010). 
Rheinberger entende que, para Bachelard, a noção de progresso não tem um fim pré-determinado, ou uma realidade última, mas constitui um movimento constante, contínuo, de produção diferencial de conhecimento. Não há para ele, que é filósofo da ciência e bioquímico, dificuldade em entender a afirmação bachelardiana de que as ciências se fazem a partir de um racionalismo aberto. Ele observa também uma radicalização do pensamento bachelardiano sobre a relação entre ciência e técnica nos livros escritos entre 1949 e 1952 . A técnica não é colocada como subproduto, ou uma derivação, da atividade científica, mas como constitutiva do modus operandi da ciência contemporânea. Há entre o espírito científico e o objeto científico um duplo movimento de interiorização e, ao mesmo tempo, exteriorização instanciado e exemplificado por instrumentos científicos. Os instrumentos são provas de conhecimento adquirido do espírito e permitem a produção de fenômenos técnicos, os objetos. Tanto o espírito quanto o objeto têm em sua formação mediação técnica.

Assim, contra à afirmação de que a epistemologia bachelardiana seria cientificista, Rheinberger afirma que a psicanálise do conhecimento trabalha com o contexto de descoberta. Para ele, com a psicanálise do conhecimento, Bachelard não propõe uma análise estrutural ou uma lógica particular do conhecimento científico, mas sim uma atividade deliberadamente psico-epistêmica. No sentido de ser uma fenomenologia do trabalho do cientista que precisa sempre transpor obstáculos epistemológicos (como os dados imediatos, as imagens primeiras) para dar origem a novos conhecimentos.

Deste modo, entendemos que a epistemologia bachelardiana ocupa lugar de destaque na história da filosofia francesa e, por isso, filósofos contemporâneos a nós ainda retomam seu pensamento, mesmo que seja para marcar um afastamento deste. As reflexões bachelardianas sobre o aspecto social das ciências são, como procuramos demonstrar, discretas e ainda carecem de análise sobretudo quanto à questão dos valores morais. Mas acreditamos que é possível ler uma ética científica nos escritos bachelardianos sobre as ciências. Esta eticidade presente na proposta bachelardiana da cidade científica tem sua origem, como procuramos demonstrar neste trabalho, em sua defesa da educação como o meio pelo qual o indivíduo pode produzir - e não apenas reproduzir - conhecimento.

A cidade científica é não apenas o lugar de divulgação de teorias e experimentações, mas também um ambiente de seleção. É nesse espaço que é definido o que é considerado ciência pelos especialistas que dele fazem parte. A especialização passa a ser, em um determinado momento, um motivo de exclusão do público diletante, interessado nas discussões sobre ciências, mas que não dispõe de recursos financeiros ou temporais para participar da cidade científica. Ou, mesmo quando de sua entrada, torna-se parte de uma região específica da comunidade. A especialização e a consequente regionalização das ciências, observadas na apresentação que fizemos da cidade científica, são analisadas de maneira positiva por nosso autor. Esta visão não se preocupa, certamente, com a socialização das ciências, mas antes com seu progresso, como processo.

\section{Considerações finais}

A abordagem bachelardiana em relação às ciências é muitas vezes criticada por seu otimismo em relação ao progresso e à sua imparcialidade referentes às questões político-sociais. Eles não atentam, entretanto, para o uso que Bachelard fez da noção de progresso e para sua repetida preocupação com o ensino de ciências na educação básica. Trata-se, então, de um pensador que, apesar de não afirmar em seus escritos um forte posicionamento político, atrela indiretamente uma proposta ético-política à sua argumentação. O otimismo bachelardiano em relação às ciências é baseado também na sua crença de que, entre todas as atividades humanas, as ciências ainda exigem uma formação em que os valores - como a honra, a coragem, a persistência - são fundamentais para sua prática.

O conceito bachelardiano de fenomenotécnica constitui a atividade científica em sua plena complexidade, isto é, em seus diferentes modos de atuação. Entretanto, para que isso pudesse ser assim afirmado, Bachelard precisou retificar elementos caros à filosofia das ciências como as noções de fenômeno, racionalismo, realismo, progresso e objetividade. Com isso, ele pretendia se aproximar, de uma maneira mais dinâmica e direta, da prática científica e, consequentemente, fazer com que a filosofia não permanecesse em atraso em relação a ela. 
A partir da crítica à forma pela qual o conhecimento científico era analisado na filosofia, Bachelard argumenta a necessidade de uma retomada da experiência no campo racional. A presença da técnica utilizada nos laboratórios como instrumento que confere certeza às proposições racionais constitui a base deste pensamento que afirma uma relação possível entre razão e experiência. Como pudemos constatar com Chimisso (2008), grande parte das polêmicas bachelardianas com a filosofia dita moderna refere-se ao uso que esta última faz de alguns conceitos já modificados pela ciência, como, por exemplo, as noções de fenômeno e substância. Assim, ao afastar-se das teorias do conhecimento anteriores, Bachelard prescreve uma epistemologia, como as noções de racionalismo aplicado e surracionalismo, que nos permitiriam pensar a ciência como fenomenotécnica. Essa proposta é por ele defendida como uma rejeição à dicotomia razão-experiência como um problema filosófico e como uma descrição da atividade científica.

Afirmamos, então, que é possível atualizar a interpretação dos escritos epistemológicos de Bachelard a partir de questões que nos são contemporâneas. Por isso, apresentamos as considerações bachelardianas para a filosofia das ciências tendo em vista o questionamento social. Ainda que não concordemos com as duras afirmações sobre uma completa anemia política no pensamento bachelardiano, entendemos que é difícil manter uma ruptura epistêmica, tal como ele propôs diante dos atuais discursos sobre ciências. Todavia, a fim de apresentar as contribuições que a epistemologia histórica ainda guarda para aqueles que se interessam pelo estudo sobre as ciências, buscamos aproximá-la em nosso trabalho dos autores dos Science Studies. Acreditamos que, com isso, podemos compreender não apenas a importância histórica da filosofia de Bachelard, mas também que é possível e necessário extrair dela novas e interessantes interpretações. 


\section{Referências bibliográficas}

BACHELARD, Gaston. Le rationalisme appliqué. Paris: PUF, 1949

. A vocação científica e a alma humana. In: O Homem perante a Ciência. Encontros Internacionais de Genebra 1952. Lisboa: Publicações Europa - América, 1967.

L'engagement rationaliste. Paris: Presses universitaires de France, 1972a.

Le matérialisme rationnel. 3.ed. Paris: PUF, $1972 \mathrm{~b}$.

Essai sur la connaissalnce approchée. 4a ed, Paris: J. Vrin, 1973.

. O racionalismo aplicado, Tradução: Nathanael C. Caixeiro. Rio de Janeiro: Zahar, 1977

. O novo espírito científico; A filosofia do não. In: Coleção Os Pensadores. Tradução: Joaquim José Moura Ramos. São Paulo: Abril Cultural, 1978.

O materialismo racional, Tradução: João Gama. Rio de Janeiro: Edições 70, 1990.

_. A formação do espírito científico: contribuição para uma psicanálise do conhecimento. Tradução: Estela dos Santos Abreu. Rio de Janeiro: Contraponto, 1996.

Ensaio sobre o conhecimento aproximado. Rio de Janeiro: Contraponto, 2004.

Estudos. Tradução: Estela dos Santos Abreu. Rio de Janeiro: Contraponto, 2008.

BRENNER, Anastasios. Les origenes françaises de la philosophie des sciences. Paris: PUF, 2003.

CHIMISSO, Cristina. From phenomenology to phenomenotechnique: the role of early twentieth-century physics in Gaston Bachelard's philosophy. Studies in History and Philosophy of Science, n.39, p.384-392, 2008.

GALISON, P. Culturas etéreas e culturas materiais. In: A ciência tal qual se faz. Org. Fernando Gil. Lisboa: Ed. João Sá da Costa, 1999.

GINGRAS, Yves. Mathématisation et exclusion: Socio-analyse de la formation des cités savantes, in Wunenburger, Jean-Jacques (éd.), Bachelard et l’épistémologie française, col. Débats philosophiques, PUF, Paris, 2001.

HACKING, I. Representar e intervir. Tradução de Pedro Rocha. Revisão de Antonio Augusto Passos Videira. Introdução de André Mendonça. RJ: EdUERJ, 2012.

HEIDEGGER, M. A Questão da Técnica. In: Ensaios e Conferências. Petrópolis: Vozes/Univ. São Francisco, 2002.

JAEGER, Werner. Paideia: a formação do homem grego. 5a ed., São Paulo: Martins Fontes, 2010.

LATOUR, Bruno; WOOLGAR, S. A vida de laboratório: a produção dos fatos científicos. Rio de Janeiro: Relume Dumará, 1997.

LATOUR, Bruno. Jamais fomos modernos: ensaio de antropologia simétrica. Tradução de Carlos Irineu da Costa. Rio de Janeiro: Editora 34, 1994.

RHEINBERGER, H. Gaston Bachelard and the notion of 'phenomenotechnique'. Perspectives on Science, n.13, p. 313$328,2005$.

. An epistemology of the concrete: Twentieth-Century Histories of Life, Duke University Press: 2010.

TORRETTI, Roberto. Estudios filosóficos: 2010-2011. Santiago do Chile: Ediciones Universidad Diego Portales, 2013.

. Fenomenotecnia y conceptualización en la epistemología de Gaston Bachelard. THEORIA 73, 2012.

VIDEIRA, A.A.P., História e Historiografia da ciência. Escritos. Ano 1, nº1, 2007

WUNENBURGER, Jean-Jacques (Org.) Gaston Bachelard: Science et poétique, une nouvelle éthique?. Paris: Hermann Éditeurs, 2013. 